\title{
Left Ventricular Assist Devices and Their Role in Cardiogenic Shock: Literature Review and Contemporary Data
}

\section{S Tzikas*, AP Evangeliou, A Boulmpou, G Loufopoulos, CE Papadopoulos and V Vassilikos}

\author{
Third Department of Cardiology, Ippokratio General Hospital, Aristotle University of Thessaloniki, \\ Thessaloniki, Greece
}

*Corresponding author: Stergios Tzikas, Third Department of Cardiology, Ippokratio General Hospital, Aristotle University of Thessaloniki, Konstantinoupoleos str. 49, 54642 Thessaloniki, Greece, Tel: +30-694-

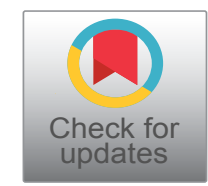
6895980

\begin{abstract}
Despite tremendous progress in the therapeutic algorithms of hemodynamically unstable patients, cardiogenic shock remains a clinical challenge with high mortality rate. Conservative management with inotropic agents remains the first-choice treatment, though it has been associated with serious adverse events and is not always adequate. Circulatory support with mechanical devices has been widely implemented in patients with cardiogenic shock during high-risk percutaneous coronary interventions or post-cardiac surgery complications and has been associated with favorable outcomes. In patients with acute decompensated heart failure, ventricular assist devices have been used to prolong the recovery period and reverse the cause of hemodynamic instability. In the present review, we discuss the current evidence on the use of percutaneous assist devices for the treatment of cardiogenic shock, plus we highlight the need for future evolution in this particular field that may permit the optimal choice of each device for different patients or clinical situations.
\end{abstract}

\section{Keywords}

Percutaneous circulatory support, Cardiogenic shock, Acute coronary syndrome, Left ventricular assist device, iVAC, Impella, ECMO

\footnotetext{
Abbreviations

CS: Cardiogenic Shock; MODS: Multiple Organ Dysfunction Syndrome; CAD: Coronary Artery Disease; AMI: Acute Myocardial Infarction; MCS: Mechanical Circulatory Support; PCI: Percutaneous Coronary Intervention; LV: Left Ventricle; RV: Right Ventricle; LVAD: Left Ventricular Assist Device; ECMO: Extracorporeal Membrane Oxygenation; VA: Venous - Arterial; IABP: Intra-Aortic Balloon Pump; ACS: Acute Coronary Syndrome
}

\section{Introduction}

Cardiogenic shock (CS) comprises a complex, critical clinical entity characterized by a dramatic decrease in cardiac output, resulting in peripheral tissue and end-organ hypoperfusion and subsequent multiple organ dysfunction syndrome (MODS) [1]. Widely accepted as a medical emergency, CS has garnered attention due to its markedly high mortality, which still exceeds $40 \%$, despite progress in diagnostic and therapeutic algorithms [2].

In the 2016 European Society of Cardiology (ESC) guidelines on acute heart failure, CS is defined as a state of persistent hypotension (systolic blood pressure $<90 \mathrm{mmHg}$ ) despite adequate fluid replacement, with concomitant signs of hypoperfusion [3]. Other CS definitions have also been proposed in the literature, such as in the IABP-SHOCK II trial, where clinical signs of impaired end-organ perfusion, such as alterations of mental status and cold extremities, plus low urine output and high lactate concentration were taken under consideration for the establishment of the diagnosis [4]. Recently, in an attempt to classify CS with an eye towards the better understanding and establishing of more efficient therapeutic algorithms, the Society for Cardiovascular Angiography and Interventions proposed a simple, easy-to-use classification of CS, dividing patients into five distinct stages (A to $E$ ), intending to refine communication between clinicians and to categorize CS cases in order to provide the optimum treat-

Citation: Tzikas S, Evangeliou AP, Boulmpou A, Loufopoulos G, Papadopoulos CE, et al. (2021) Left Ventricular Assist Devices and Their Role in Cardiogenic Shock: Literature Review and Contemporary Data. Int J Clin Cardiol 8:215. doi.org/10.23937/2378-2951/1410215

Accepted: January 28, 2021: Published: January 30, 2021

Copyright: (c) 2021 Tzikas S, et al. This is an open-access article distributed under the terms of the Creative Commons Attribution License, which permits unrestricted use, distribution, and reproduction in any medium, provided the original author and source are credited. 
ment [5].

The vast improvement in healthcare service quality through the past decades has led to significant demographic ageing of the developed countries, while coronary artery disease (CAD) still remains a major health burden with high death rates [6]. Acute myocardial infarction (AMI) belongs among the leading causes of $\mathrm{CS}$, raising in-hospital mortality and healthcare costs [7]. Even so, one could highlight a variety of potential CS causes, namely acute decompensated heart failure, valvular and pericardial diseases, arrhythmias and toxicity [2].

CS has been an item of interest in international guidelines of clinical practice and published scientific statements [8]. Nevertheless, all available data point towards a particularly vague perception of CS as a clinical entity, while its recognition and its optimal therapeutic algorithm remain controversial; hence, one could highlight a plethora of inconsistencies between ESC and American Heart Association (AHA)/American College of Cardiology (ACC) guideline recommendations $[1,3,9]$. Those differences comprise the debate on the routine use of pulmonary artery catheter in CS for diagnosis and management and the use of inotropes as first-line vasoactive agents [9]. Notwithstanding, both guidelines agree on the application of mechanical circulatory support (MCS) when pharmacological therapy fails, despite the lack of strong clinical evidence on survival improvement [9].

The present review describes the use of MCS devices in the treatment of CS and summarizes all published cases of patients with hemodynamic instability undergoing high-risk percutaneous coronary interventions $(\mathrm{PCl})$ or cardiac surgery who were managed with the aid of IVAC2L device.

\section{Mechanical Circulatory Support Devices}

Percutaneously inserted MCS devices are designed to support the left ventricular dysfunction by reducing the pressures and volumes of the left ventricle (LV) as well as increasing end-organ perfusion and coronary blood flow in hemodynamically unstable patients $[10,11]$. The technical features of different types of percutaneous assist devices are presented in Table 1. The majority of these devices can be inserted percutaneously via the femoral or the axillary artery and aspirate blood from the LV to the ascending aorta, decrease LV preload and succeed the LV support. The devices with greater blood flow, as the iVAC3L and the Impella $5.0 \mathrm{~L}$ are inserted with surgical preparation of the vascular site. While only the Impella RP and extracorporeal membrane oxygenation (ECMO) can support the right ventricular dysfunction according to the manufacturer, there are reports of other devices which have been used for the unloading of the right ventricle (RV) [12].

\section{Extracorporeal membrane oxygenation (ECMO)}

ECMO was the first device able to provide circulato- ry and simultaneous respiratory support, counting over seven decades of implementation. An ECMO device nowadays consists of the oxygenator, a gas exchange component, the inflow and outflow tubing, the pump and the hand crank. The closed ECMO circuit withdraws percutaneously via the femoral vein the deoxygenated blood from the right atrium or a central vein and returns the oxygenated blood via a second cannula to the arterial or venous system. More specifically, venous-arterial (VA) ECMO system reinfuses the fully saturated and decarboxylated blood to the iliac artery via the femoral artery. The cannulation of the femoral artery is demanding and needs careful, accurate manipulations in order to avoid limb ischemia [13]. An extra condition to be considered is the watershed phenomenon. The antegrade blood flow from the heart competes with the retrograde oxygenated blood flow from the cannula of the iliac artery of the ECMO. When the watershed phenomenon is formed low in thoracic aorta, the retrograde oxygenated blood from the ECMO does not contribute to the coronary and cerebral blood perfusion.

Over the last decades, a significantly increasing tendency in the use of ECMO has been observed. This might be a result of the easy way of implantation of the ECMO system, even at the bedside, and the ability of concurrent transportation of the supported patient to an advanced medical care unit.

Cardiopulmonary failure after cardiothoracic surgery, referred as post-cardiotomy CS, remains the most prominent indication of use of the ECMO system [14]. Although the benefit of ECMO implementation remains controversial in AMI-induced CS [15], it has been proven in refractory CS as a valuable temporary solution [16]. ECMO could be additionally employed as a bridge to lung transplantation in lung disease [17], and as a bridge to heart transplantation in fulminant myocarditis [18]. Another variant, the Veno-Venous ECMO is used in severe respiratory failure-like conditions $[19,20]$. Towards this direction, similarly demanding cases consist of patients in ECMO with shock, pulmonary edema and LV failure who need LV decompression. In order to reduce the effect of the watershed form, avoid coronary and cerebral hypoperfusion and increase cardiac output, a combination of ECMO and IVAC2L might be very profitable $[21,22]$.

\section{Impella}

The Impella series are percutaneously catheter-based mechanical circulatory assist devices that can provide up to $6 \mathrm{~L}$ cardiac output and decrease LV preload. The Impella device is inserted in a peripheral artery, femoral or axillary, and is placed across the aortic valve in the LV. There are various types of Impella devices, depending on the provided stroke volume (Table 1). Impella RP is indicated in right ventricular failure after left ventricular assist device (LVAD) implantation, AMI, or acute pulmo- 


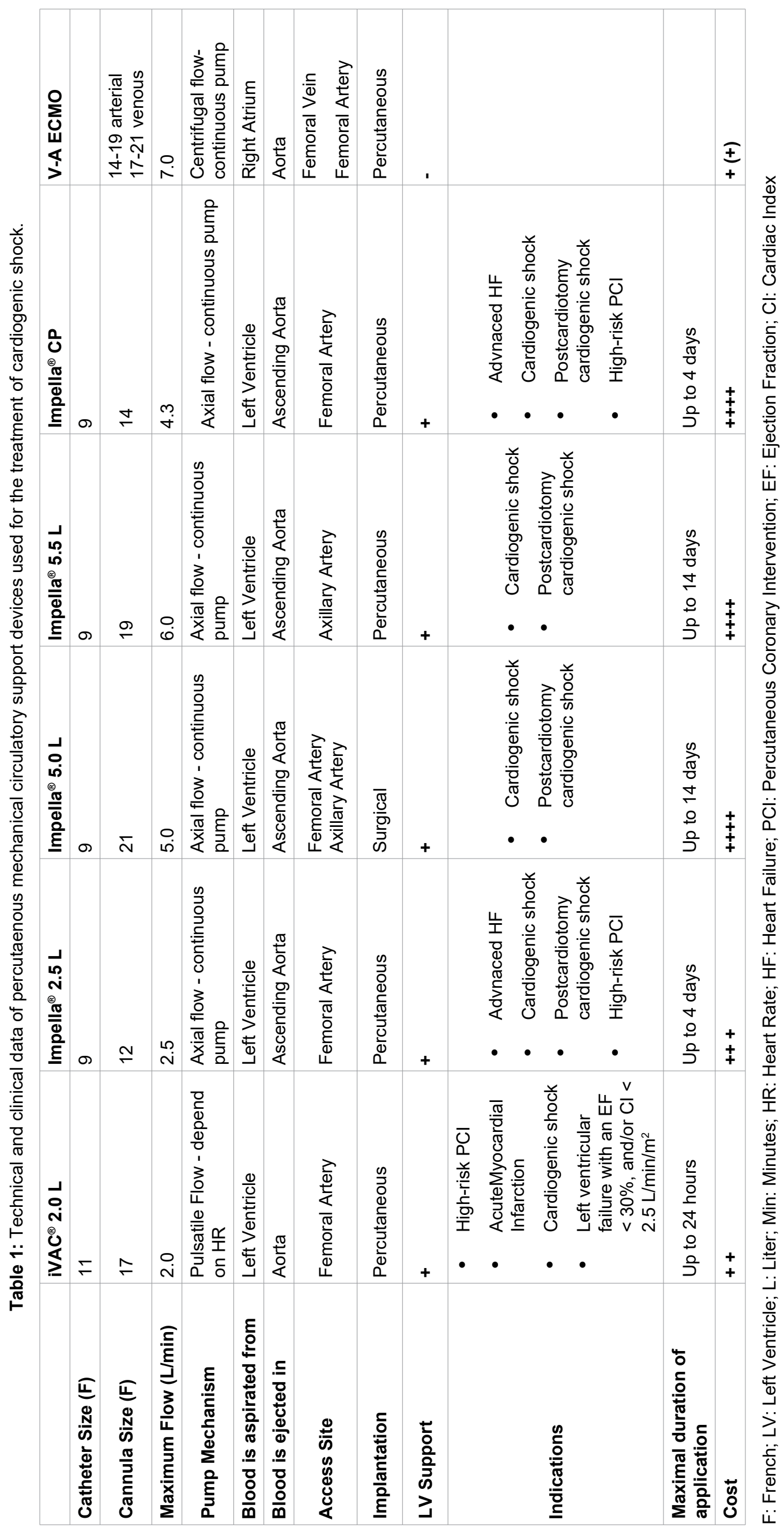


nary embolism [23-35]. In patients with end-stage heart failure or in severe cases of myocarditis, Impella seems to be highly effective as a bridge both to recovery or to a final treatment, such as transplantation or surgical heart pump implantation $[26,27]$. Furthermore, Impella seems to be capable of aiding the stabilization of patients with aortic valve stenosis undergoing transcatheter aortic valve implantation [28].

Several published studies demonstrated the significant circulatory support and anti-ischemic myocardial protection that Impella could provide in the context of high-risk PCI [29-32]. Recent studies suggest the use of Impella devices in patients with CS or cardiac arrest caused by AMI in order to improve outcomes $[33,34]$. The early implantation of Impella prior to $\mathrm{PCl}$ is associated with prolonged survival and higher rates of successful revascularization [35]. In addition, no difference in 30 days mortality between Impella and ECMO was observed in patients with CS after AMI [36]. Nevertheless, the role of Impella in AMI-induced CS still remains a controversial issue, as highlighted in a recently published metanalysis [37]; at the same time, another recent study suggested high mortality rates despite the use of Impella [38]. Well-organized, prospective, multicenter ongoing trials will shed light on this lack of data [39].

\section{iVAC2L}

The PulseCath iVAC2L (PulseCath BV, Amsterdam, Netherlands) is a novel pulsatile circulatory support system that accepts blood from the LV and ejects it in the ascending aorta. The device consists of a flow catheter with an extracorporeal pneumatic dual chamber and a patented rotating two-way valve [40]. The extracorporeal membrane pump is connected to a mainstream IABP console, acting as a pneumatic driver of the pumpand generate up to $2.0 \mathrm{~L} / \mathrm{min}$ output. The pulsatile mechanism of action is in synchrony with the cardiac cycle and aspirates blood from the LV simultaneously with the cardiac systole. At higher heart rate, the output will be decreased since the short-time of diastolic phase will not offer sufficient time for the ejection [40]. The main indication is CS due to AMI, while it has also been used in patients with post-cardiac surgery or viral infection-induced CS and for prevention of hemodynamic instability during high-risk PCl [41-43]. The device has been designed for the temporary support of the LV after percutaneous insertion through the femoral artery, while the support of RV after insertion through the pulmonary artery trunk during cardiac surgery has also been described [12].

Through a systematic search of the existing literature, several studies and case reports implying the iVAC device support were identified (Table 2) $[12,21,22,43$ 48], while indications of use, type of vascular access, pre- and post-implantation hemodynamical parameters, as well as potential complications of the implanta- tion, are presented in Table 1.

\section{Discussion}

In the last decades, technological evolution has enabled mechanical LV assist devices to play a major role in the treatment of CS and in the hemodynamic support during high-risk PCI procedures. Moreover, they seem to prevent circulatory collapse and provide the necessary time for the patient to overcome a potentially reversible condition. As previously described, percutaneously inserted assist devices for LV dysfunction have been additionally used for the support of RV in patients with post-cardiac surgery CS which were treated with IABP [12]. The insertion technique's adequacy through the right cavities and the efficacy of these devices are still under debate, nevertheless, the patient would probably meet a significant benefit, potentially leading to a complete recovery. The simultaneous use of LVAD with VA ECMO has also been endorsed by a newly published case supporting the concept of potential future applications of dual assist devices. The EC-iVAC (simultaneous use of ECMO and IVAC) and ECMELLA (ECMO and Impella) approaches may be considered as an option among patients in CS in urgent need of immediate LV support [21,22]. Moreover, a recently published international multicenter cohort study evaluated the clinical outcomes in patients with CS treated with VA ECMO with or without LV unloading with the use of Impella showed that the mechanical LV support was associated with lower mortality [49].

\section{Implantation timing}

In all instances, there is general agreement that a patient in CS requires early recognition, resuscitation and stabilization; attentive monitoring is crucial, whilst fluid challenge and adequate pharmacologic support with vasopressors and inotropic agents are considered as first-line therapeutic options. In addition, MCS may be needed in order to maintain systemic perfusion, stabilize hemodynamic status and act as a bridge to further therapeutic actions [3,50,51]. Nevertheless, the correct timing of implementing MCS in CS patients still remains controversial [52]. The development and validation of a novel algorithm predicting the progression of CS as well as guiding the physician towards the optimal implantation of a MCS device is of paramount importance. The hemodynamical support at the early-stage of the CS is proven to hold a significant benefit for the patient and seem to offer a major time extension with an eye towards recovery [53].

\section{Insertion and accurate placement in the LV}

The different technical features of the various MCS device may constitute an obstacle in the selection of the assist device, since the size of the sheath and the diameter of the femoral or axillary artery could determine the incision site as well as the type of the device that 


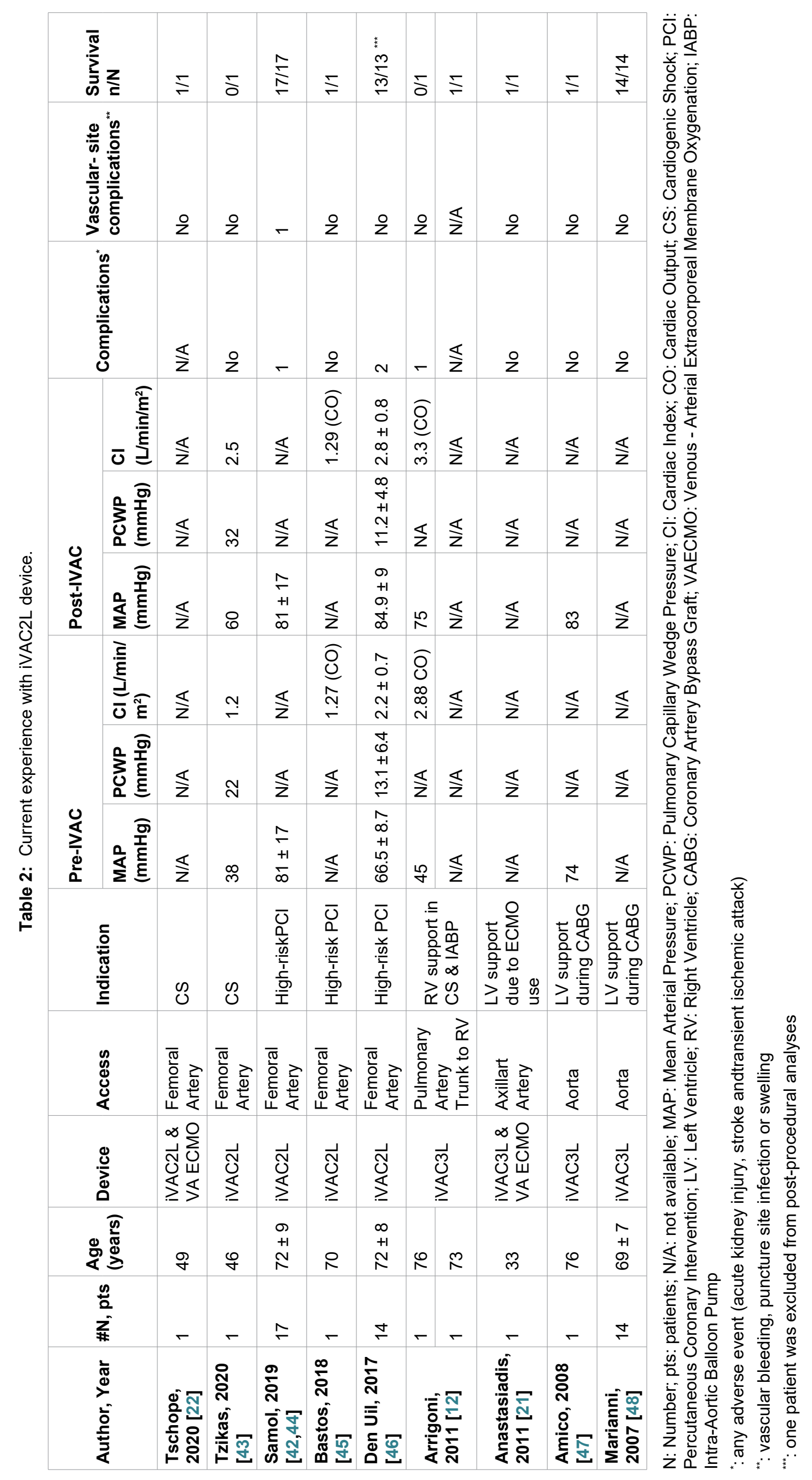


will be used. As presented in Table 1, the need of a larger sheath is mainly associated with the maximal output of each device, as larger devices demand wider sheath. Notwithstanding, the Impella CP is the only device with maximal blood flow greater than $4.0 \mathrm{~L} / \mathrm{min}$ with a cannula size of 14 French which can be implanted for up to 4 days in patients with CS or for the prevention of hemodynamic instability during high-risk $\mathrm{PCl}$ procedures. The right placement of the device is crucial in order to properly aspirate blood from the LV and eject it over the aortic valve. The placement position of the device should be confirmed with the use of the transesophageal echocardiography or with aortography. The Impella system features a pig-tail loop in the top of the device rendering the implantation inside the LV easier. In the published literature, various methods for the right placement have been described, such as the insertion of a pigtail catheter over the aortic valve and subsequent aortography assessment in order properly place the two-way valve (outlet) over the aortic valve $[44,54,55]$.

\section{Complications of use and removal of the device}

The disadvantage of axial flow Impella devices in contrast to the pulsatile iVAC, is that they have been associated with a significantly higher risk of hemolysis (10\% of patients during first 24 hours) due to the high rotational speed of the axial flow pump [56-60]. Hemolysis has also been linked with worse prognosis in patients with acute coronary syndrome [61-63]. Tschope, et al. reported a case of significant hemolysis after the simultaneous use of VA ECMO and Impella devices, while the substitution of Impella with iVAC supported the hemodynamic status of the patient efficiently and resulted in a slighter hemolytic effect [22].

Furthermore, additional disadvantages of the percutaneous assist devices are the controversial selection of the most appropriate site for vascular catheter insertion, as well as the complications during the process or after the removal of the sheath. This depends on the size of the device, the diameter of the vessel, as well as the medical history of the patient. Moreover, the removal of the cannula is of paramount importance and should be performed by a trained physician as it might be accompanied by major complications. The most usual complications during the removal of the device are bleeding and arterial perforation which will need surgical reconstruction. Novel vascular closure devices for large-bore femoral arterial puncture have also been developed in the last years and can be valuable in order to provide safe hemostasis. In a recent meta-analysis, the use of these closure devices was associated with a significantly lower incidence of groin hematomas or pseudoaneurysms, as well as with impaired hemostasis time when compared to extrinsic compression [64].

All in all, there is lack of clinical studies that directly compare percutaneous assist devices. Further research ought to be rendered in order to cover the gaps in ev- idence, provide guidance on device selection and way of implantation, depending on the hemodynamic status and individual history of each patient.

\section{Conflict of Interest}

Nothing to declare.

\section{Funding}

None.

\section{References}

1. Diepen SV, Katz JN, Albert NM, Henry TD, Jacobs AK, et al. (2017) Contemporary management of cardiogenic shock: A scientific statement from the American Heart Association. Circulation 136: e232-e268.

2. Tehrani BN, Truesdell AG, Psotka MA, Rosner C, Singh R, et al. (2020) A standardized and comprehensive approach to the management of cardiogenic shock. JACC Heart Fail 8: 879-891.

3. Ponikowski P, Voors AA, Anker SD, Bueno H, Cleland JGF, et al. (2016) 2016 ESC Guidelines for the diagnosis and treatment of acute and chronic heart failure: The Task Force for the diagnosis and treatment of acute and chronic heart failure of the European Society of Cardiology (ESC) developed with the special contribution of the Heart Failure Association (HFA) of the ESC. Eur heart J 37: 2129-2200.

4. Thiele H, Zeymer U, Neumann F-J, Ferenc M, Olbrich H-G, et al. (2012) Intraaortic balloon support for myocardial infarction with cardiogenic shock. N Engl J Med 367: 12871296.

5. Baran DA, Grines CL, Bailey S, Burkhoff D, Hall SA, et al. (2019) SCAI clinical expert consensus statement on the classification of cardiogenic shock: This document was endorsed by the American College of Cardiology (ACC), the American Heart Association (AHA), the Society of Critical Care Medicine (SCCM), and the Society of Thoracic Surgeons (STS) in April 2019. Catheter Cardiovasc Interv 94: 29-37.

6. Reynolds K, Go AS, Leong TK, Boudreau DM, Cassidy-Bushrow AE, et al. (2017) Trends in incidence of hospitalized acute myocardial infarction in the Cardiovascular Research Network (CVRN). Am J Med 130: 317-327.

7. Khalid L, Dhakam SH (2008) A review of cardiogenic shock in acute myocardial infarction. Curr Cardiol Rev 4: 34-40.

8. Jones TL, Nakamura K, McCabe JM (2019) Cardiogenic shock: Evolving definitions and future directions in management. Open Heart 6: e000960.

9. van Diepen S, Thiele H (2019) An overview of international cardiogenic shock guidelines and application in clinical practice. Curr Opin Crit Care 25: 365-370.

10. Burkhoff D, Naidu SS (2012) The science behind percutaneous hemodynamic support: $A$ review and comparison of support strategies. Catheter Cardiovasc Interv 80: 816-829.

11. Remmelink M, Sjauw KD, Henriques JPS, de Winter RJ, Koch KT, et al. (2007) Effects of left ventricular unloading by Impella recover LP2.5 on coronary hemodynamics. Catheter Cardiovasc Interv 70: 532-537.

12. Arrigoni SC, Kuijpers M, Mecozzi G, Mariani MA (2011) PulseCath $^{(R)}$ as a right ventricular assist device. Interactive Cardiovascular and Thoracic Surgery 12: 891-894.

13. Bonicolini E, Martucci G, Simons J, Raffa GM, Spina C, 
et al. (2019) Limb ischemia in peripheral veno-arterial extracorporeal membrane oxygenation: A narrative review of incidence, prevention, monitoring, and treatment. Crit Care 23: 266.

14. Wang L, Wang H, Hou X (2018) Clinical outcomes of adult patients who receive extracorporeal membrane oxygenation for postcardiotomy cardiogenic shock: A systematic review and meta-analysis. J Cardiothorac Vasc Anesth 32 2087-2093.

15. Vallabhajosyula S, Prasad A, Bell MR, Sandhu GS, Eleid $M F$, et al. (2019) Extracorporeal membrane oxygenation use in acute myocardial infarction in the United States, 2000 to 2014. Circ Heart Fail 12: e005929.

16. Guenther S, Theiss HD, Fischer M, Sattler S, Peterss S, et al. (2014) Percutaneous extracorporeal life support for patients in therapy refractory cardiogenic shock: Initial results of an interdisciplinary team. Interact Cardiovasc Thorac Surg 18: 283-291.

17. Hayanga JWA, Hayanga HK, Holmes SD, Ren Y, Shigemura N, et al. (2019) Mechanical ventilation and extracorporeal membrane oxygenation as a bridge to lung transplantation: Closing the gap. J Heart Lung Transplant 38: 1104-1111.

18. Ting $\mathrm{M}$, Wang $\mathrm{CH}$, Tsao $\mathrm{Cl}$, Huang $\mathrm{SC}$, $\mathrm{Chi} \mathrm{NH}$, et al. (2016) Heart transplantation under mechanical circulatory support for acute fulminant myocarditis with cardiogenic shock: 10 years' experience of a single center. Transplant Proc 48: 951-955.

19. Patel B, Arcaro M, Chatterjee S (2019) Bedside troubleshooting during venovenous extracorporeal membrane oxygenation (ECMO). J Thorac Dis 11: S1698-S1707.

20. Camboni D, Philip A, Schmid C, Loforte A (2019) Double, triple and quadruple cannulation for veno-arterial extracorporeal membrane oxygenation support: Is there a limit? Ann Cardiothorac Surg 8: 151-159.

21. Anastasiadis $\mathrm{K}$, Chalvatzoulis $\mathrm{O}$, Antonitsis $\mathrm{P}$, Tossios $\mathrm{P}$, Papakonstantinou C (2011) Left ventricular decompression during peripheral extracorporeal membrane oxygenation support with the use of the novel iVAC pulsatile paracorporeal assist device. Ann Thorac Surg 92: 2257-2259.

22. Tschope C, Alogna A, Faragli A, Klingel K, Schmidt G, et al. (2020) Case report first-in-man method description: Left ventricular unloading with iVAC2L during veno-arterial extracorporeal membrane oxygenation: From veno-arterial extracorporeal membrane oxygenation to ECMELLA to ECiVAC $^{(R)}$. Front Cardiovasc Med 7: 563448.

23. Gramegna M, Beneduce A, Bertoldi LF, Pagnesi M, Marini C, et al. (2020) Impella RP support in refractory right ventricular failure complicating acute myocardial infarction with unsuccessful right coronary artery revascularization. Int $J$ Cardiol 302: 135-137.

24. Anderson MB, Goldstein J, Milano C, Morris LD, Kormos $R L$, et al. (2015) Benefits of a novel percutaneous ventricular assist device for right heart failure: The prospective RECOVER RIGHT study of the Impella RP device. J Heart Lung Transplant 34: 1549-1560.

25. Zuin M, Rigatelli G, Daggubati R, Nguyen T, Roncon L (2020) Impella RP in hemodynamically unstable patients with acute pulmonary embolism. J Artif Organs 23: 105-112.

26. Annamalai SK, Esposito ML, Jorde L, Schreiber T, Hall SA, et al. (2018) The impella microaxial flow catheter is safe and effective for treatment of myocarditis complicated by cardiogenic shock: An analysis from the global cVAD Registry. J Card Fail 24: 706-710.
27. Cheng R, Tank R, Ramzy D, Azarbal B, Chung J, et al. (2019) Clinical outcomes of impella microaxial devices used to salvage cardiogenic shock as a bridge to durable circulatory support or cardiac transplantation. ASAIO J 65: 642-648.

28. Almalla M, Kersten A, Altiok E, Marx N, Schröder JW (2020) Hemodynamic support with Impella ventricular assist device in patients undergoing TAVI: A single center experience. Catheter Cardiovasc Interv 95: 357-362.

29. Dixon SR, Henriques JPS, Mauri L, Sjauw K, Civitello A, et al. (2009) A prospective feasibility trial investigating the use of the Impella 2.5 system in patients undergoing highrisk percutaneous coronary intervention (The PROTECT I Trial): Initial U.S. experience. JACC Cardiovasc Interv 2: 91-96.

30. Hritani AW, Wani AS, Olet S, Lauterbach CJ, Allaqaband $S Q$, et al. (2019) Secular trend in the use and implementation of impella in high-risk percutaneous coronary intervention and cardiogenic shock: A real-world experience. J Invasive Cardiol 31: E265-E270.

31. Maini B, Naidu SS, Mulukutla S, Kleiman N, Schreiber T, et al. (2012) Real-world use of the Impella 2.5 circulatory support system in complex high-risk percutaneous coronary intervention: The USpella Registry. Catheter Cardiovasc Interv 80: 717-725.

32. O'Neill BP, Cohen MG, Basir MB, Schreiber T, Kapur NK, et al. (2019) Outcomes among patients transferred for revascularization with impella for acute myocardial infarction with cardiogenic shock from the cVAD Registry. Am J Cardiol 123: $1214-1219$.

33. Davidsen C, Packer EJS, Løland KH, Rotevatn S, Nygreen EL, et al. (2019) Impella use in acute myocardial infarction complicated by cardiogenic shock and cardiac arrest: Analysis of 10 years registry data. Resuscitation 140: 178-184.

34. Sieweke JT, Berliner D, Tongers J, Napp LC, Flierl U, et al. (2020) Mortality in patients with cardiogenic shock treated with the Impella CP microaxial pump for isolated left ventricular failure. Eur Heart J Acute Cardiovasc Care 9: 138-148.

35. O'Neill WW, Schreiber T, Wohns DHW, Rihal C, Naidu SS, et al. (2014) The current use of Impella 2.5 in acute myocardial infarction complicated by cardiogenic shock: Results from the USpella Registry. J Interv Cardiol 27: 1-11.

36. Karami M, den Uil CA, Ouweneel DM, Scholte NT, Engström AE, et al. (2020) Mechanical circulatory support in cardiogenic shock from acute myocardial infarction: Impella CP/5.0 versus ECMO. Eur Heart J Acute Cardiovasc Care 9: 164-172.

37. lannaccone M, Albani S, Giannini F, Colangelo S, Boccuzzi GG, et al. (2020) Short term outcomes of Impella in cardiogenic shock: A review and meta-analysis of observational studies. Int J Cardiol.

38. Ouweneel DM, de Brabander J, Karami M, Sjauw KD, Engström AE, et al. (2019) Real-life use of left ventricular circulatory support with Impella in cardiogenic shock after acute myocardial infarction: 12 years AMC experience. Eur Heart J Acute Cardiovasc Care 8: 338-349.

39. Udesen NJ, Moller JE, Lindholm MG, Eiskjaer H, Schafer A, et al. (2019) Rationale and design of DanGer shock: Danish-German cardiogenic shock trial. Am Heart J 214: 60-68.

40. Van Mieghem NM, Daemen J, Lenzen MJ, Zandstra R, Malkin O, et al. (2015) The PulseCath iVAC 2L left ventricular assist device: Conversion to a percutaneous transfemoral approach. Eurolntervention 11: 835-839. 
41. Bastos MB, van Wiechen MP, Van Mieghem NM (2020) PulseCath iVAC2L: Next-generation pulsatile mechanical circulatory support. Future Cardiol 16: 103-112.

42. Samol A, Luani B, Kaese S, Wiemer M (2019) TCT-321 head-to-head comparison of a pulsatile and a continuous flow left ventricular assist device in high-risk $\mathrm{PCl}$ setting: iVAC2L Versus Impella 2.5. J Am Coll Cardiol 74.

43. Tzikas S, Papadopoulos $\mathrm{CH}$, Evangeliou AP, Vassilikos $\mathrm{V}$ (2020) First implantation of the pulsatile left ventricular assist device iVAC2L in a heart failure patient infected with influenza type A. Hellenic J Cardiol.

44. Samol A, Schmidt S, Zeyse M, Wiemer M, Luani B (2019) High-risk $\mathrm{PCl}$ under support of a pulsatile left ventricular assist device - First German experience with the iVAC2L system. Int J Cardiol 297: 30-35.

45. Bastos MB, Daemen J, Van Mieghem N (2018) Haemodynamic impact of a new pulsatile mechanical circulatory support in high-risk coronary stenting. Eurolntervention 14: 824-825.

46. den Uil CA, Daemen J, Lenzen MJ, Maugenest AM, Joziasse L, et al. (2017) Pulsatile iVAC 2L circulatory support in high-risk percutaneous coronary intervention. Eurolntervention 12: 1689-1696.

47. Amico A, Brigiani MS, Vallabini A, Ferrante B, Marzovillo A, et al. (2008) PulseCath, a new short-term ventricular assist device: Our experience in off-pump coronary artery bypass graft surgery. J Cardiovasc Med (Hagerstown) 9: 423-426.

48. Mariani MA, Diephuis JC, Kuipers MJH, Gianoli M, Grandjean JG (2007) Off-pump coronary artery bypass graft surgery with a pulsatile catheter pump for left ventricular dysfunction. Ann Thorac Surg 84: 690-692.

49. Schrage B, Becher PM, Bernhardt A, Bezerra H, Blankenberg $S$, et al. (2020) Left ventricular unloading is associated with lower mortality in patients with cardiogenic shock treated with veno-arterial extracorporeal membrane oxygenation: Results from an International, Multicenter Cohort Study. Circulation 142: 2095-2106.

50. Ergle K, Parto P, Krim SR (2016) Percutaneous ventricular assist devices: A novel approach in the management of patients with acute cardiogenic shock. Ochsner J 16: 243-249.

51. Schafer A, Burkhoff D, Bauersachs J (2019) Haemodynamic simulation and the effect of early left ventricular unloading in pre-shock acute coronary syndrome. ESC Heart Fail 6: 457-463.

52. Jiritano F, Lo Coco V, Matteucci M, Fina D, Willers A, et al (2020) Temporary mechanical circulatory support in acute heart failure. Card Fail Rev 6: e01.

53. Van Diepen S, Katz JN, Albert NM, Henry TD, Jacobs AK, et al. (2017) Contemporary management of cardiogenic shock: A scientific statement from the American Heart Association. Circulation 136: e232-e268.

54. Samol A, Schmidt S, Zeyse M, Wiemer M (2018) First successful prevention of cardiopulmonary resuscitation during high-risk percutaneous coronary intervention by use of a pulsatile left ventricular assist device: Baptism of fire of the iVAC2L device: A case report. Eur Heart J Case Rep 2: yty005.

55. Samol A, Schmidt S, Zeyse M, Durrwald S, Wiemer M (2017) First high-risk percutaneous coronary intervention under use of the iVAC2I system in Germany. Future Cardiol 13: $117-123$

56. Seyfarth M, Sibbing D, Bauer I, Frohlich G, Bott-Flugel L, et al. (2008) A randomized clinical trial to evaluate the safety and efficacy of a percutaneous left ventricular assist device versus intra-aortic balloon pumping for treatment of cardiogenic shock caused by myocardial infarction. J Am Coll Cardiol 52: 1584-1588.

57. Cardozo S, Ahmed T, Belgrave K (2015) Impella induced massive hemolysis: Reemphasizing echocardiographic guidance for correct placement. Case Rep Cardiol 2015: 464135.

58. Sibbald M, Dzavik V (2012) Severe hemolysis associated with use of the Impella LP 2.5 mechanical assist device. Catheter Cardiovasc Interv 80: 840-844.

59. Sjauw KD, Konorza T, Erbel R, Danna PL, Viecca M, et al. (2009) Supported high-risk percutaneous coronary intervention with the Impella 2.5 device the Europella registry. J Am Coll Cardiol 54: 2430-2434.

60. Lauten A, Engström AE, Jung C, Empen K, Erne P, et al. (2013) Percutaneous left-ventricular support with the Impella-2.5-assist device in acute cardiogenic shock: Results of the Impella-EUROSHOCK-registry. Circ Heart Fail 6: 23-30.

61. Dalton HJ, Cashen K, Reeder RW, Berg RA, Shanley TP, et al. (2018) Hemolysis during pediatric extracorporeal membrane oxygenation: Associations with circuitry, complications, and mortality. Pediatr Crit Care Med 19: 1067-1076.

62. Robertson JO, Okada S, Joseph SM, Itoh A, Silvestry SC (2013) Left ventricular assist device-related hemolysis and acute pancreatitis: A case series. J Heart Lung Transplant 32: $846-848$

63. Ravichandran AK, Parker J, Novak E, Joseph SM, Schilling JD, et al. (2014) Hemolysis in left ventricular assist device: A retrospective analysis of outcomes. J Heart Lung Transplant 33: 44-50.

64. Robertson L, Andras A, Colgan F, Jackson R (2016) Vascular closure devices for femoral arterial puncture site haemostasis. Cochrane Database Syst Rev 3. 